\title{
Smoking Cessation and Breastfeeding Promotion Education for Prenatal Providers in West Virginia
}

Kimberly Greenfield

West Virginia University

Follow this and additional works at: https://researchrepository.wvu.edu/etd

\section{Recommended Citation}

Greenfield, Kimberly, "Smoking Cessation and Breastfeeding Promotion Education for Prenatal Providers in West Virginia" (2014). Graduate Theses, Dissertations, and Problem Reports. 318.

https://researchrepository.wvu.edu/etd/318

This Thesis is protected by copyright and/or related rights. It has been brought to you by the The Research Repository @ WVU with permission from the rights-holder(s). You are free to use this Thesis in any way that is permitted by the copyright and related rights legislation that applies to your use. For other uses you must obtain permission from the rights-holder(s) directly, unless additional rights are indicated by a Creative Commons license in the record and/ or on the work itself. This Thesis has been accepted for inclusion in WVU Graduate Theses, Dissertations, and Problem Reports collection by an authorized administrator of The Research Repository @ WVU. For more information, please contact researchrepository@mail.wvu.edu. 
Smoking Cessation and Breastfeeding Promotion Education for

Prenatal Providers in West Virginia

Kimberly Greenfield, MPH

Project Report Submitted to the School of Medicine at West Virginia University

In partial fulfillment of the requirements for the degree of

Master of Science in Clinical and Translational Science

Dr. Ilana R. Azulay Chertok, PhD, MSN, RN, Chair

Dr. Stacey Culp PhD

Dr. Fred Minnear PhD

Department of Clinical and Translation Science

Morgantown, West Virginia

2014

Keywords: Prenatal smoking cessation, Breastfeeding promotion

Permission to reprint sections of the original manuscript was approved by the West Virginia Medical Journal who maintain the Copyright 2014 


\begin{abstract}
Smoking Cessation and Breastfeeding Promotion Education for Prenatal Providers in West Virginia
\end{abstract}

Kimberly Greenfield MPH

Background: West Virginia has the highest prenatal smoking cessation rate in the United States and is among the states with the lowest breastfeeding rate in the nation. West Virginia also faces health disparities and limited prenatal health resources, especially in at-risk areas. In an effort to improve resources in at-risk areas of the state, the "Health Education for Prenatal Providers in Appalachia” (HEPPA), using the ACOG 5As smoking cessation intervention and breastfeeding promotion, was developed for delivery to interprofessional providers.

Method: The HEPPA program delivered to healthcare and social service providers in four contiguous counties was evaluated by comparing pre-test and post-test survey responses regarding knowledge, attitude, and behaviors of smoking cessation and breastfeeding promotion. Results: Findings show that respondents' attitudes towards both prenatal smoking cessation and breastfeeding promotion improved. Knowledge levels of prenatal smoking effects significantly increased. 


\section{Table of Contents}

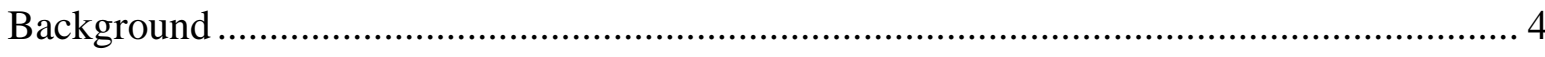



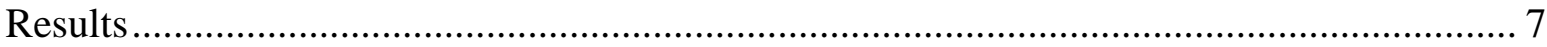

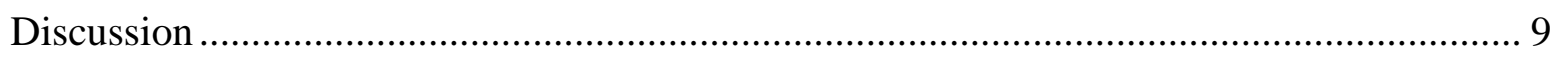

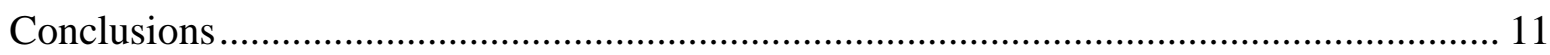

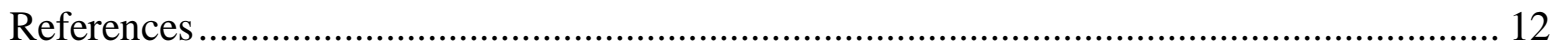

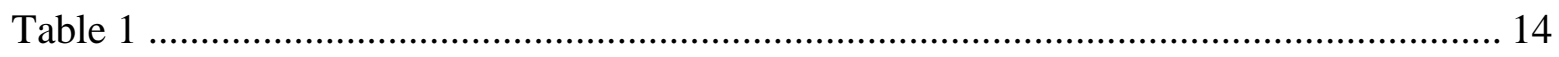




\section{Background}

West Virginia faces health disparities related to limited health resources, lack of healthcare providers, and challenges of access to care, especially in distressed and at-risk areas where prenatal health services are minimal. In some counties, there is such a shortage of healthcare providers and perinatal services that there are no obstetricians to provide prenatal care. This situation obligates women to travel significant distances to access prenatal care in counties with larger cities, limiting pregnant women's access to prenatal care and education in the state.

The inclusion of smoking cessation into the training of healthcare providers has been recommended by obstetric professional organizations (ACOG, 2005). Despite recommendations, health professional education and training are deficient in this aspect of health promotion (Price, 2008; Springer, 2008). Healthcare providers in Appalachia lack adequate training or institutional support to effectively address smoking cessation among their pregnant clients and families. Furthermore, research conducted in Appalachia has found that obstetric healthcare providers do not sufficiently engage their pregnant clients in smoking reduction and cessation intervention programs (Bailey \& Cole, 2009).

Pregnancy is an ideal time for helping women stop smoking as it is considered a "teachable moment" when motivation for healthy lifestyle changes is high. The frequent and regular prenatal care schedule facilitates the relay of constant and consistent health promotion messages by the various health providers and social service professionals involved in care. Trained healthcare providers' consistent and persistent messages regarding the risks of prenatal smoking along with support for smoking cessation efforts have been associated with reduced smoking (Melvin et al.,_2000). Healthcare and service providers' messages and support delivered during perinatal visits and interactions regarding reducing prenatal smoking exposure as well as engaging in other positive lifestyle changes during and following pregnancy can positively influence women's health decisions, attitudes, and behaviors.

Smoking in pregnancy is a modifiable risk factor that is dose dependent; the higher the exposure, the higher the risk (Salihu et al., 2003). Research has shown that maternal smoking in pregnancy increases the risk for placental dysfunction (Aliyu et al., 2009). In Appalachia, there is an increased risk for poor perinatal outcomes as well as an increased risk for low birth weight associated with prenatal smoking, with a compounding effect (Bailey \& Byrom 2007; Bailey \& Cole 2009; Chertok, Luo \& Anderson, 2011). Prenatal health behaviors are factors associated 
with negative birth outcomes, especially in these regions. West Virginia has the highest prenatal smoking prevalence rate in the United States at 32\% compared to the national rate of $12 \%$ (Tong, et al., 2009). Prenatal exposure to smoking is a modifiable risk factor associated with increased infant morbidity and mortality.

Breastfeeding is another modifiable behavior that is health protective and immunologically promotional. Infants who do not receive human milk have an increased risk of morbidity and mortality (Gartner, et al., 2005). The national average breastfeeding initiation rate is $76.5 \%$ and the 3-month exclusive breastfeeding rate is $37.7 \%$ (CDC, 2013). Breastfeeding rates among women in Appalachia are lower than the national average (Wiener \& Wiener, 2011), with West Virginia's breastfeeding initiation rate at $60.5 \%$ and 3-month exclusive breastfeeding rate at $27.2 \%$, respectively (CDC, 2013). Additionally, research supports a relationship between the two modifiable risk factors of prenatal smoking and lack of breastfeeding among women in different areas of Appalachia (Bailey \& Wright, 2011; Chertok, Luo, Culp, et al., 2011), further increasing infant risk for poor outcomes.

Breast milk is uniquely suited to the human infant's nutritional needs and is a live substance with unparalleled immunological and anti-inflammatory properties that protect against a host of illnesses and diseases for both mothers and infants. Research has shown that breastfeeding decreases the prevalence of many acute and chronic diseases in infants including respiratory and gastrointestinal infections, as well as promotes neurological development (Gartner, 2005). While the benefits of breastfeeding are well researched there is a significant discrepancy between breastfeeding rates in Appalachia compared to national rates. A population-based survey found that Appalachian breastfeeding prevalence rates were significantly lower than the national average (Wiener \&_Wiener, 2011). Factors for lack of breastfeeding initiation in West Virginia were found to be lack of resources, lack of support, and lower socioeconomic status (Wiener \& Wiener, 2011).

In an effort to reduce prenatal smoking exposure and promote breastfeeding in the state of West Virginia, an intervention was developed to target at-risk rural regions where there was a relative lack of prenatal care resources. The purpose of the pilot study was to evaluate the delivery of the "Health Education for Prenatal Providers in Appalachia" (HEPPA) to health and 
social service providers in four contiguous at-risk counties in West Virginia with health disparities to augment the knowledge and training of the providers serving in these areas.

\section{Method}

The educational intervention program trains healthcare and social service providers in the identified at-risk counties of West Virginia how to implement and incorporate into care the HEPPA program that includes the evidence-based American College of Obstetricians and Gynecologists (ACOG) 5As brief smoking cessation intervention (ACOG 2005), along with breastfeeding promotion. HEPPA includes the evidence-based approach of smoking reduction in addition to smoking cessation for those who are not willing or able to completely quit, with the emphasis that cessation is preferred (Melvin, et al. 2000). Due to the limited prenatal healthcare providers in the designated at-risk counties, Calhoun, Clay, Roane, and Wirt counties, other healthcare and social service providers who directly interact with pregnant women were invited to participate in the intervention program. County-specific data reveal even higher rates relative to the overall state rate: Calhoun 36\%, Clay 36\%, Roane 32\%, Wirt 38\% in West Virginia (WV DHHR, 2006). Additionally, the investigators identified primary obstetric providers affiliated with regional hospitals where most of the pregnant women were reported to receive their prenatal and delivery services to engage them in the HEPPA program to facilitate a common, comprehensive message regarding prenatal smoking cessation. The program was conducted in another part of Appalachia in collaboration with a research team at East Tennessee State University lead by Dr. Beth Bailey, while the focus of this paper is the findings of the program conducted in West Virginia, through West Virginia University lead by Dr. Ilana Chertok, with support from the Appalachian Regional Commission.

The training program included an in-person 1.5-hour training session taught by the trained team at clinics and other designated sites in each of the counties. Out of consideration for the busy schedules of the various providers and agents, the investigators offered flexible meeting times such as lunch-time or evening sessions, as well as serving as the in-service training for any given site. Delivery and training methods of the program included lectures, handouts, discussion of case-studies using an interdisciplinary team approach, and referral of participants to the online HEPPA website with information, resources, and links (http://www.etsu.edu/heppa/default.aspx). 
To evaluate the HEPPA program, nonparametric tests were conducted to compare preintervention, immediate post-intervention, and 1-3 month post-intervention surveys of the providers' baseline and post-training knowledge and behaviors regarding prenatal smoking cessation counseling. To measure the change in smoking cessation counseling behaviors, a majority of the questions were used from the 24-item reliability tested evidence-based Smoking Cessation Counseling (SCC) scale (alpha=0.955) (Newhouse, Himmelfarb, \& Liang, 2011) with revisions and additions relevant to various healthcare and social service providers working with pregnant women and their families in rural Appalachia. The revised SCC had a high reliability score (alpha=0.978). To evaluate the change in breastfeeding knowledge and attitude, the assessment developed for use among physicians was used (Freed, Clark, Sorenson, Lohr, Cefalo, \& Curtis, 1995). Comparisons were made to examine the differences for the overall group as well as between the healthcare providers and the social service providers. Furthermore, access to the HEPPA website ("hits") was tracked.

\section{Results}

A total of 140 various providers participated in the intervention in West Virginia, with 120 completing the pretest $(85.7 \%)$ and 76 completing the posttest $(54.2 \%)$. The majority of the participants were female $(96.2 \%)$ and white $(98.4 \%)$. The average age was $43 \pm 11.7$ years. The educational level of the participants reflected a high educational level relative to the state population with $69.4 \%$ of the participants having completed college and/or professional education, $19.1 \%$ completed some college, and $11.5 \%$ completed high school. Most of the participants $(81.5 \%)$ had children of their own and $81.7 \%$ were living with a partner or spouse. Among the 38 people who had children and answered the questions regarding breastfeeding, 30 (78.9\%) breastfed compared to $8(21.1 \%)$ who did not, with an average duration of 9.4 months. Regarding the providers' smoking behavior among those who responded (92.8\%), 7.7\% currently smoked, $0.8 \%$ used other tobacco products, $20.0 \%$ quit smoking, and $71.5 \%$ never smoked. Among the respondents, $17.1 \%$ lived with a smoker. The various types of providers included physicians (7.0\%), nursing staff (32.0\%), mid-level providers (14.1\%), social workers (4.7\%), dieticians $(3.1 \%)$, smoking cessation counselors $(2.3 \%)$, health counselors $(3.9 \%)$, community service providers such as resource coordinators, WVU Extension agents, and pastors $(32.8 \%)$. The participants reported their places of work to include health clinics and practices 
(53.8\%), health departments (6.2\%), WIC offices (8.5\%), WVU Extension and community resources offices $(7.6 \%)$, and other community agencies $(23.8 \%)$.

A majority of the participants $(92.1 \%)$ responded that they believed that the overall prenatal healthy lifestyles educational program was very effective or effective. The participants positively rated the overall quality of the program as excellent or very good (47.3\%), good $(46.1 \%)$, or fair $(6.6 \%)$ and the content of the program as very good or excellent $(46.0 \%)$, good $(47.4 \%)$, and fair $(6.6 \%)$. Specifically regarding prenatal smoking cessation education, $90.8 \%$ responded that they felt that their knowledge level of prenatal smoking improved as a result of the program. Similarly, most of the respondents reported an improved attitude toward smoking cessation for pregnant women and their families: strongly agree $61.8 \%$, agree $18.4 \%$, neutral $9.2 \%$, and disagree $10.5 \%$, while all of the respondents (100.0\%) expressed that the program would be useful for others working with pregnant women. An assessment of HEPPA website hits indicates that there were 820 visits by 316 unique visitors, $80 \%$ accessed the "For Professionals" page, 83 viewed the uploaded HEPPA presentation, and 23 downloaded the physician toolkit. Participants' self-assessed confidence and skills in providing smoking cessation counseling and their knowledge regarding prenatal smoking cessation favorably changed using a 10-point scale, although the results were not significant. Confidence in providing breastfeeding counseling significantly improved over time for providers working with pregnant and postpartum women using Wilcoxon Signed Rank Tests $(\mathrm{z}=-2.75, \mathrm{p}=0.006, \mathrm{z}=-3.13$, $\mathrm{p}=0.002$, respectively).

McNemar's test was used to compare the differences in breastfeeding knowledge in breastfeeding counseling prior to and after the intervention. Preliminary results demonstrate that there was a significant improvement in one breastfeeding knowledge question, regarding a woman breastfeeding while taking antibiotics $(\mathrm{p}=0.013)$ and a significant improvement in providers' confidence levels in providing breastfeeding assistance to new mothers $(\mathrm{p}=0.005)$ and breastfeeding education to pregnant women $(\mathrm{p}=0.001)$. There were significant increases among the overall group in the frequency of six items on the revised SCC regarding specific smoking cessation counseling behaviors, using Wilcoxon Signed Rank Tests (Table 1). At baseline, there were significant differences between the healthcare and social service providers regarding frequency of using the 5As steps, with healthcare providers having higher rates of Ask $(\mathrm{p}<0.001)$, Advise $(\mathrm{p}<0.001)$, Assess $(\mathrm{p}=0.001)$, Assist $(\mathrm{p}<0.001)$, and Arrange $(\mathrm{p}=0.028)$ using 
Mann-Whitney $\mathrm{U}$ tests. The differences were not significant in the post-intervention period. Comparing pretest and posttest, the frequency with which the overall group of providers engaged their pregnant clients in the Advise and Assist steps of the 5As smoking cessation program significantly increased ( $\mathrm{z}=-2.434, \mathrm{p}=0.015$ and $\mathrm{z}=-2.707, \mathrm{p}=0.007$, respectively) (Table 2), although there were no significant differences between the types of providers regarding frequency of using the 5 As program following the intervention.

\section{Discussion}

The HEPPA program delivered to healthcare and social service providers piloted in the four at-risk counties of West Virginia demonstrated effectiveness in improving the frequency of behaviors that indicate incorporation of prenatal smoking cessation into prenatal care and into interactions with pregnant clients, with only a significant improvements in select knowledge and confidence scores of breastfeeding education and smoking cessation counseling.

There were significantly increased rates of the overall groups' use of the smoking cessation Advise and Assist steps in the 5As program. The revised SCC tool was useful in assessing healthcare and social service providers' changes in specific behaviors. Six items were significantly improved following the intervention including three SCC questions and three pregnancy-specific additions to the SCC tool. The added pregnancy-specific questions were beneficial in tailoring the tool to the concerns and focus of pregnant women. Describing risks of secondhand smoke and the potential negative impact of maternal smoking on the fetus may motivate a woman to reduce her prenatal smoking exposure as she learns that pregnancy does not entirely shield the fetus from harmful effects of environmental exposures. Additionally, by providing practical tips and strategies for smoking cessation in pregnancy, the provider is affording the woman more tools to help her in her efforts to reduce prenatal smoking exposure. The providers had a nearly significant increase in the reporting of following up with pregnant women who smoke which is an important aspect of consistency in care in the 5As program. These findings indicate that the HEPPA program contributed to an increase in smoking cessation counseling behaviors by various providers working with pregnant women living in areas where prenatal resources are limited. 
The lack of significant differences between the healthcare and social service providers regarding engagement in the $5 \mathrm{As}$ program following significant differences in the baseline for each of the 5As steps suggests that the HEPPA program enabled the social service providers to use the 5As program at a level similar to that of the healthcare providers. This finding supports inclusion of various healthcare and social service providers working in rural at-risk communities, thereby broadening the available and accessible resources. The inclusive approach of the HEPPA program helped to reach out to community workers who engage with pregnant women but are often not viewed as providers of prenatal care in delivery of the health promotion training. These providers can serve to provide consistent smoking cessation messages and resources for pregnant women in at-risk communities where access to resources is limited. The program encouraged an atmosphere of networking and interprofessional communication. Healthcare and social service providers were able to identify shared resources within their respective counties and collaborate on health promotion efforts, creating a more cohesive, comprehensive, and inclusive approach to care. The providers also positively rated the HEPPA program and described it as important and helpful for other providers working with pregnant women. The combination of delivery methods was also a benefit of the program, as participants appreciated having the program brought to their respective counties and having the option of retrieving materials and resources through the online component of the program, thereby facilitating access to information.

Limitations of the study relate to the lack of reliability of the breastfeeding knowledge and attitudes assessment tool with a recommendation that a valid and reliable tool be developed for use among various types of providers. Additionally, participants were lost to follow-up despite reminders that were sent to the participants and to their worksites. When working with community participants, it is recommended to explain the importance of follow-up to encourage continued participation. Finding a convenient time for the various providers was challenging and time consuming, although reaching out to them in their places of work appeared to facilitate delivery of the program. Further work in the area of delivery of health promotional training in rural at-risk areas where healthcare resources are limited is critical to supporting and advancing the health education of populations living in those areas. 


\section{Conclusions}

Prenatal smoking and relatively low rates of breastfeeding continue to be a serious public health challenge in rural West Virginia. The HEPPA program was designed to deliver a cohesive message about prenatal smoking cessation, smoking exposure reduction, and breastfeeding promotion for pregnant women and their families in rural counties of the state. The HEPPA program was designed to increase healthcare and social service providers' implementation and use of strategies and the 5As steps in smoking cessation education of their pregnant clients. While this pilot program has shown promising results, there is a need for continued and expanded efforts to augment access to health resources and reduce health disparities in rural areas of the state using an interdisciplinary approach. 


\section{References}

Aliyu, M.H., Lynch, O., Wilson, R.E., Alio, A.P., Kristensen, S., Marty, P.J., Whiteman, V.E., \& Salihu, H.M. (2009). Association between tobacco use in pregnancy and placenta-associated syndromes: a population-based study. Arch Gynecol Obstet, 283, 729-734. American College of Obstetricians and Gynecologists (ACOG). (2005). ACOG Committee Opinion No. 316: Smoking cessation during pregnancy. Obstet Gynecol, 106, 883-888. Bailey, B.A. \& Byrom, A.R. (2007). Factors predicting birth weight in a low-risk risk sample: the role of modifiable pregnancy healthy behaviors. Matern Child Health J, 11, 173-179. Bailey, B.A. \& Cole, L.K.J. (2009a). Rurality and birth outcomes: findings from southern Appalachia and the potential role of pregnancy smoking. J Rural Health, 25, 141-149.

Bailey, B.A. \& Cole, L.K.J. (2009b). Are obstetricians following best-practice guidelines for addressing pregnancy smoking? Results from northeast Tennessee. South Med J, 102, 894-899. Centers for Disease Control and Prevention (CDC). (2013). Breastfeeding report card. Accessed on April 28, 2014 at http://www.cdc.gov/breastfeeding/pdf/2013BreastfeedingReportCard.pdf Chertok, I.R., Luo, J., \& Anderson, R.H. (2011). Association between changes in smoking habits in subsequent pregnancy and infant birth weight in West Virginia. Matern Child Health J, 15, 249-254.

Flower, K. B., Willoughby, M., Cadigan, R. J., Perrin, E. M., \& Randolph, G. (2008). Understanding breastfeeding initiation and continuation in rural communities: a combined qualitative/quantitative approach. Maternal and Child Health Journal, 12(3), 402-414.

Freed, G. L., Clark, S. J., Sorenson, J., Lohr, J. A., Cefalo, R., \& Curtis, P. (1995). National assessment of physicians' breast-feeding knowledge, attitudes, training, and experience. JAMA, 273(6), 472-476.

Gartner LM, Morton J, Lawrence RA, Naylor AJ, O'hare D, Schanler RJ, Eidelman AI. American Academy of Pediatrics. (2005). Breastfeeding and the use of human milk. Pediatrics, 115, 496-506.

Melvin, C.L., Dolan-Mullen, P., Windsor, R.A., Whiteside, H.P. \& Goldenberg, R.L. (2000).

Recommended cessation counselling for pregnant women who smoke: A review of the evidence. Tobacco Control, 9 (Suppl III), iii80-iii84.

Price JH, Mohamed I, Jeffery JD. Tobacco intervention training in American College of NurseMidwives accredited education programs. J Midwifery Womens Health. 2008;53:68-74. 
Newhouse, R.P., Himmelfarb, C.D., \& Liang, Y. (2011). Psychometric testing of the smoking cessation counseling scale. Journal of Nursing Scholarship, 43, 405-411.

Salihu, H.M., Aliyu, M.H., Pierre-Louis, B.J., \& Alexander, G.R. (2003). Levels of excess infant deaths attributable to maternal smoking in the United States. Matern Child Health J, 7, 219-227. Springer CM, Tannert Niang KM, Matte TD, et al. Do medical students know enough about smoking to help their future patients? Assessment of New York City fourth-year medical students' knowledge of tobacco cessation and treatment for nicotine addiction. Acad Med. 2008;83:982-989.

Tong, V.T., Jones, J.R., Dietz, P.M., D’Angelo, D., Bombard, J.M., \& CDC. (2009). Trends in smoking before, during, and after pregnancy- Pregnancy Risk Assessment Monitoring System (PRAMS), United States, 31 sites, 2000-2005. MMWR, 58 (SS-4), 1-30.

US Department of Health and Human Services. (2011). The Surgeon General's call to action to support breastfeeding.

Wiener, R. C., \& Wiener, M. A. (2011). Breastfeeding prevalence and distribution in the USA and Appalachia by rural and urban setting. Rural \& Remote Health, 11(2).

West Virginia Department of Health and Human Resources (WV DHHR). (2006). Table 21:

Pregnancy risk factors, cesarean sections, delivery complications, congenital anomalies, and/or abnormal conditions of the newborn, percent by county of residence, West Virginia resident births, 2006. Accessed on 6/19/2014 at http://www.wvdhhr.org/bph/hsc/pubs/vital/2006/vs_21.htm 
Table 1. Change in frequency of smoking cessation behaviors and strategies based on the median pre-test and post-test scores of the modified SCC tool for healthcare and social service providers working with pregnant clients. $\mathrm{N}=120$

Item

I advise pregnant smokers to set a quit date

$\operatorname{Pr}$

I advise pregnant smokers to get support from family, friends and coworkers

$\begin{array}{llll}1.0 & 3.0 & -1.424 & 0.154\end{array}$

$\begin{array}{lll}1.0 & 3.0 & -1.543\end{array}$

0.123

$\begin{array}{lllll}\text { I review past quit attempts - what helped, what led to relapse } & 1.0 & 3.0 & -2.757 & 0.006\end{array}$

I help pregnant smokers anticipate challenges, particularly during the critical first few weeks

$\begin{array}{llll}1.0 & 3.0 & -2.757 & 0.006\end{array}$

I help pregnant smokers anticipate nicotine withdrawal

$\begin{array}{llll}1.0 & 2.0 & -1.625 & 0.104\end{array}$

I identify reasons for quitting and benefits of quitting

$3.0 \quad 4.0 \quad-1.268$

0.205

I describe effects of smoking on the fetus*

$1.0 \quad 4.0 \quad-2.115$

0.034

I advise cessation resources for household members of pregnant $\begin{array}{lllll}\text { women who smoke } & 1.0 & 3.0 & -1.308 & 0.191\end{array}$

I recommend use of nicotine gum for pregnant smokers, unless contraindicated

$\begin{array}{lll}1.0 & 1.0 & -0.604\end{array}$

0.546

I use cessation materials that are appropriate by age, culture, language, education, and pregnancy status $\quad 1.0$

I follow-up with pregnant smokers about smoking cessation at future visits 1.0

I advise pregnant smokers if relapse occurs, they should repeat

the quit attempt- it is part of the quitting process 1.0
I advise pregnant smokers that if relapse occurs, they should review the circumstances and learn from the experience

I provide the number for the toll-free Quitline

1.0
3.0

$\begin{array}{lll}1.0 & 3.0 & -0.771\end{array}$

0.441

$\begin{array}{lll}.0 & 3.0 & -1.922\end{array}$

0.055

I refer pregnant smokers to online resources for smoking cessation programs

$\begin{array}{llll}1.0 & 2.0 & -1.117 & 0.264\end{array}$

I refer pregnant smokers to resources in their county for smoking cessation

$\begin{array}{lll}1.0 & 3.0 & -1.123\end{array}$

0.261

I provide practical tips and strategies for quitting to pregnant smokers*

1.0

3.0

$-2.646$

0.008

I advise pregnant smokers to quit

4.0

I ask pregnant smokers if they are willing to quit or cut down 3.0

If pregnant smokers are willing to quit, I provide resources and assistance

$4.0 \quad-0.918$

0.359

If pregnant smokers are not willing to quit, I provide resources

and help identify barriers

$4.0 \quad-1.508$

0.132

25

I assess pregnant clients' smoking (tobacco use)

$-3.030$

0.002

I document pregnant clients' smoking (tobacco use)

3.0

1.0

$-0.361$

0.718

I assess pregnant clients' secondhand smoke exposure*

1.5

1.0

$-0.271$

0.787

I advise pregnant women to avoid secondhand smoke and smokers*

$\begin{array}{lll}2.5 & 3.0 & -1.978\end{array}$

0.280

$2.0-1.080$

0.048

*Added question for use with pregnant clients. 
